\title{
PEWARNAAN TITIK KETAKTERATURAN LOKAL INKLUSIF PADA GRAF KIPAS, GRAF PETASAN, DAN GRAF MATAHARI
}

\section{An Inclusive Local Irregularity Vertex Coloring of Fan Graph, Firecracker Graph, and Sun Graph}

\author{
A. Ma'arif ${ }^{\text {* }}$, M. G. Halim ${ }^{2}$, S. Indriani ${ }^{3}$, A.I Kristiana ${ }^{4}$, R. Alfarisi ${ }^{5}$ \\ 1,2,3,4 Pendidikan Matematika, FKIP, Universitas Jember \\ ${ }^{5}$ Pendidikan Guru Sekolah Dasar, FKIP, Universitas Jember \\ Jln. Kalimantan 3 No 37 Kampus Tegalboto, Jember, Jawa Timur, 68121, Indonesia
}

Corresponding author e-mail: 1* anwarmaarif2@gmail.com

\begin{abstract}
Abstrak
Diberikan $G(V, E)$ adalah graf sederhana dan terhubung dengan $V(G)$ adalah himpunan titik dan $E(G)$ adalah himpunan sisi. Sebuah pemetaan $l: V(G) \rightarrow\{1,2, \ldots, k\}$ merupakan fungsi label dan $w^{i}: V(G) \rightarrow N$ adalah fungsi bobot pewarnaan titik ketakteraturan lokal inklusif, dengan $w^{i}(v)=l(v)+\Sigma_{u \in N(v)} l(u)$. Jumlah warna minimum yang dihasilkan dari pewarnaan titik ketakteraturan lokal inklusif sebuah graf $G$ disebut bilangan kromatik titik ketakteraturan lokal inklusif, dinotasikan dengan $\chi_{\text {lis }}^{i}(G)$. Pada artikel ini, kita akan membahas terkait pewarnaan titik ketakteraturan lokal inklusif dan menemukan bilangan kromatik pada beberapa graf khusus, yang meliputi graf kipas $\left(F_{n}\right)$, graf petasan $\left(F_{n, 4}\right)$, dan graf matahari $\left(S L_{n}\right)$.
\end{abstract}

Kata Kunci: Pewarnaan Titik Ketakteraturan Lokal Inklusif, Graf Kipas, Graf Petasan, dan Graf Matahari

Abstract

Let $G(V, E)$ is a simple graph and connected where $V(G)$ is vertex set and $E(G)$ is edge set. A mapping $l: V(G) \rightarrow\{1,2, \ldots, k\}$ as vertex $k$-labeling and function $w^{i}: V(G) \rightarrow N$ is inclusive local irregularity vertex coloring, with $w^{i}(v)=l(v)+\sum_{u \in N(v)} l(u)$. The minimum number of colors produced from inclusive local irregularity vertex coloring of graph $G$ is called inclusive chromatic number local irregularity, denoted by $\chi_{\text {lis }}^{i}(G)$ . On this paper, we learn about the inclusive local irregularity vertex coloring and determine the chromatic number on some special graphs, namely fan graph $\left(F_{n}\right)$, firecracker graph $\left(F_{n, 4}\right)$, and sunlet graph $\left(S L_{n}\right)$.

Keywords: An Inclusive Local Irregularity Vertex Coloring, Fan Graph, Firecracker Graph, and Sunlet Graph

Submitted: $04^{\text {th }}$ July $2021 \quad$ Accepted: $11^{\text {th }}$ November 2021




\section{PENDAHULUAN}

Semua graf pada penelitian ini adalah graf sederhana dan terhubung. Diberikan graf $G(V, E)$ adalah graf terhubung dengan orde $n$ dengan $V(G)$ adalah himpunan titik dan $E(G)$ adalah himpunan sisi [1]. Teori graf memiliki beberapa topik pembahasan diantaranya pelabelan graf dan pewarnaan graf. Pelabelan graf adalah sebuah pemberian label pada setiap elemen dari graf $G$, yaitu pada titik atau sisi atau keduanya dari graf $G$ [2]. Pewarnaan graf merupakan pemberian warna pada setiap elemen dari graf $G$, sehingga elemen yang bertetangga memiliki warna yang berbeda. Terdapat tiga macam pewarnaan dalam teori graf, yaitu pewarnaan titik, pewarnaan sisi, dan pewarnaan wilayah [3].

Pada artikel ini akan membahas mengenai pewarnaan titik pada graf $G$, dimana setiap titik yang bertetangga memiliki warna yang berbeda atau yang biasa dikenal pewarnaan titik proper [4]. Jumlah warna minimum yang dihasilkan dari pewarnaan graf disebut dengan bilangan kromatik, dinotasikan dengan $\chi(G)$ [5]. Terdapat kasus khusus dalam pewarnaan graf yaitu pewarnaan titik ketakteraturan lokal inklusif. A.I Kristiana dkk (2020) [6] telah mendefinisikan tentang pewarnaan titik ketakteraturan lokal inklusif sebagai berikut:

Definisi 1. [6] Diberikan $l: V(G) \rightarrow\{1,2, \ldots, k\}$ adalah fungsi label dan $w^{i}: V(G) \rightarrow N$ adalah fungsi bobot pewarnaan titik ketakteraturan lokal inklusif dengan $w^{i}(v)=l(v)+\sum_{u \in N(v)} l(u)$. Pelabelan $l$ dikatakan sebagai pewarnaan titik ketakteraturan lokal inklusifjika :

(i) $\operatorname{Opt}(l)=\min \left\{\max \left\{l_{a}\right\}\right\} ; l_{a}$; adalah pelabelan titik ketakteraturan lokal inklusif

(ii) Untuk setiap titik $u v \in E(G), w^{i}(u) \neq w^{i}(v)$.

Definisi 2.[6] Jumlah warna minimum yang dihasilkan dari pewarnaan titik ketakteraturan lokal inklusif sebuah graf $G$ disebut bilangan kromatik titik ketakteraturan lokal inklusif, dinotasikan dengan $\chi_{\text {lis }}^{i}(G)$.

Pada artikel ini, untuk memudahkan dalam menemukan pewarnaan titik ketakteraturan lokal inklusif pada sebuah graf maka akan digunakan definisi, lemma, proposisi, dan observasi sebagai berikut :

Lemma 1.[6] Diberikan graf $G$ adalah graf sederhana dan terhubung, maka $\chi_{\text {lis }}^{i}(G) \geq \chi_{\text {lis }}(G)$

Proposisi 1[7] Diberikan graf $F_{n}$ merupakan sebuah graf kipas, untukn $\geq 4$ maka bilangan kromatik ketakteraturan lokalnya adalah $\chi_{l i s}\left(F_{n}\right)=4$.

Proposisi 2.[7] Diberikan graf $S L_{n}$ merupakan sebuah graf matahari, untukn $\geq 4$ maka bilangan kromatik ketakteraturan lokalnya adalah

$$
\chi_{l i s}\left(S L_{n}\right)=\left\{\begin{array}{l}
3, \text { untuk } n \text { genap } \\
5, \text { untuk } n \text { gasal }
\end{array}\right. \text {. }
$$

Observasi 1. Diberikan graf $F_{n, 4}$ merupakan sebuah graf petasan, untuk $n \geq 4$ maka bilangan kromatik ketakteraturan lokalnya adalah $\chi_{l i s}\left(F_{n, 4}\right)=5$.

A. I. Kristiana dkk [6] telah melakukan penelitian terkait pewarnaan titik ketakteraturan lokal inklusif pada beberapa graf sederhana, yang meliputi graf lintasan, graf lingkaran dan graf bintang. Selanjutnya U.A. Anwar dkk [8] telah menemukan bilangan kromatik ketakteraturan lokal inklusif dari graf ilalang, graf $\mathrm{H}-$ bintang, dan graf bintang ganda. Tujuan dari penelitian ini adalah untuk menentukan pewarnaan titik ketakteraturan lokal inklusif dan bilangan kromatik ketakteraturan lokal inklusif pada beberapa graf khusus. Pada artikel ini akan dilakukan penelitian terkait pewarnaan titik ketakteraturan lokal inklusif dan menentukan bilangan kromatik ketakteraturan lokal inklusif pada graf kipas $\left(F_{n}\right)$, graf petasan $\left(F_{n, 4}\right)$,dan graf matahari $\left(S L_{n}\right)$. 


\section{METODE PENELITIAN}

Metode yang digunakan dalam penelitian ini adalah metode pendeteksi pola dan metode deduksi aksiomatik. Metode pendeteksi pola digunakan untuk merumuskan pola dari bilangan kromatik ketakteraturan lokal inklusif pada beberapa graf yang akan diteliti. Sedangkan metode deduksi aksiomatik digunakan dengan menerapkan prinsip-prinsip pembuktian deduktif yang berlaku dalam logika matematika dengan menggunakan aksioma, lemma, dan teorema yang sudah ada kemudian diterapkan dalam penyelesaian dari suatu permasalahan yang berkaitan dengan pewarnaan titik ketakteraturan lokal inklusif.

\section{HASIL DAN PEMBAHASAN}

Dalam artikel ini, kami membahas bilangan kromatik titik ketakteraturan lokal inklusif pada graf kipas, graf petasan, dan graf matahari, adapun beberapa teorema yang dihasilkan sebagai berikut:

Theorem 1. Diberikan $F_{n}$ adalah graf kipas dengan $n \geq 4$ maka $\chi_{l i s}^{i}\left(F_{n}\right)=4$.

Bukti. Diketahui $F_{n}$ merupakan graf kipas dengan himpunan titik $V\left(F_{n}\right)=y \cup\left\{x_{i} ; 1 \leq i \leq n\right\}$ dan himpunan sisi $E\left(F_{n}\right)=\left\{y x_{i} ; 1 \leq i \leq n\right\} \cup\left\{x_{i} x_{i+1} ; 1 \leq i \leq n-1\right\}$. Sehingga kardinalitas titik dan sisi memiliki nilai masing - masing yaitu $\left|V\left(F_{n}\right)\right|=n+1$ dan $\left|E\left(F_{n}\right)\right|=2 n-1$. Untuk setiap $v \in V\left(F_{n}\right)$, jika titik $y$ dan $x_{i}$ dilabeli dengan 1 maka menghasilkan $w^{i}\left(x_{i}\right)=l(y)+l\left(x_{i-1}\right)+l\left(x_{i}\right)+l\left(x_{i+1}\right)=4$ dan $w^{i}\left(x_{i+1}\right)=l(y)+l\left(x_{i}\right)+l\left(x_{i+1}\right)+l\left(x_{i+2}\right)=4$ sehingga titik - titik tersebut memiliki bobot titik yang sama, sedangkan diketahui bahwa pada grafik kipas titik $x_{i}, x_{i+1}, x_{n}$ adalah titik - titik yang bertetangga. Kondisi ini bertentangan dengan definisi dimana $w^{i}\left(x_{i}\right) \neq w^{i}\left(x_{i+1}\right)$ sehingga $\operatorname{opt}(l)=2$. Untuk menunjukkan batas atas, didefinisikan $l: V(G) \rightarrow\{1,2\}$ sebagai berikut :

$$
\begin{gathered}
l\left(x_{i}\right)=\left\{\begin{array}{c}
1, \text { untuk } i \text { gasal } \\
2, \text { untuk } i \text { genap }
\end{array}\right. \\
l(y)=1
\end{gathered}
$$

Sehingga $\operatorname{opt}(l)=2$ dan fungsi bobot sebagai berikut :

$$
\begin{gathered}
w^{i}\left(x_{i}\right)=\left\{\begin{array}{l}
4, \text { untuk } i=1 \text { dan } i=n \\
5, \text { untuk } i \text { genap } \\
6, \text { untuk } i \text { gasal }
\end{array}\right. \\
w^{i}\left(y_{i}\right)=\left\{\begin{array}{l}
\frac{n}{2}+n+1, \text { untuk } n \text { genap } \\
2 n-\frac{n-1}{2}, \text { untuk } n \text { gasal }
\end{array}\right.
\end{gathered}
$$

Dari hasil diatas didapatkan batas atas, $\left|w^{i}\left(V\left(F_{n}\right)\right)\right| \leq 4$. Selanjutnya, dari Lemma 1.1. dan Proposisi 1.1. sebagai batas bawah menunjukkan bahwa $\chi_{\text {lis }}^{i}\left(F_{n}\right) \geq \chi_{\text {lis }}\left(F_{n}\right)=4$. Berdasarkan batas atas dan batas bawah menghasilkan nilai $4 \leq \chi_{l i s}^{i}\left(F_{n}\right) \leq 4$, sedemikian sehingga $\chi_{l i s}^{i}\left(F_{n}\right)=4$. Sehingga pembuktian telah selesai. 


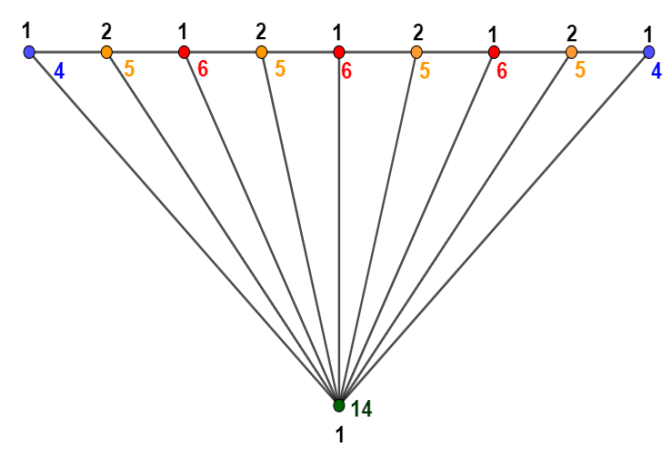

Gambar 1. Pewarnaan Titik Ketakteraturan Lokal Inklusif Graf Kipas $\chi_{l i s}^{i}\left(F_{9}\right)=4$

Theorem 2. Diberikan $F_{n, 4}$ adalah grafpetasan dengan $n \geq 4$ maka $\chi_{l i s}^{i}\left(F_{n, 4}\right)=5$.

Bukti. Diketahui $F_{n, 4}$ merupakan graf petasan dengan himpunan titik $V\left(F_{n, 4}\right)=\left\{x_{i} ; 1 \leq i \leq n\right\} \cup$ $\left\{y_{i} ; 1 \leq i \leq n\right\} \cup\left\{z_{i, j} ; 1 \leq i \leq n, 1 \leq j \leq 2\right\}$ dan himpunan $\operatorname{sisi} \quad E\left(F_{n, 4}\right)=\left\{x_{i} x_{i+1}, ; 1 \leq i \leq n-1\right\} \cup$ $\left\{x_{i} y_{i} ; 1 \leq i \leq n\right\} \cup\left\{y_{i} z_{i, j} ; 1 \leq i \leq n, 1 \leq j \leq 2\right\}$. Sehingga kardinalitas titik dan sisi memiliki nilai masing masing yaitu $\left|V\left(F_{n, 4}\right)\right|=4 n$ dan $\left|E\left(F_{n, 4}\right)\right|=4 n-1$. Untuk setiap $v \in V\left(F_{n, 4}\right)$, jika titik $x_{i}$ dan $y_{i}$ dilabeli dengan 1 maka menghasilkan $w^{i}\left(x_{i}\right)=l\left(x_{i-1}\right)+l\left(x_{i}\right)+l\left(y_{i}\right)+l\left(x_{i+1}\right)=4$ dan $w^{i}\left(x_{i+1}\right)=l\left(x_{i}\right)+l\left(x_{i+1}\right)$ $+l\left(y_{i+1}\right)+l\left(x_{i+2}\right)=4$ sehingga titik - titik tersebut memiliki bobot titik yang sama, sedangkan diketahui bahwa pada graf petasan titik $x_{i}$ dan $x_{i+1}$ adalah titik - titik yang bertetangga. Kondisi ini bertentangan dengan definisi dimana $w^{i}\left(x_{i}\right) \neq w^{i}\left(x_{i+1}\right)$ sehingga $\operatorname{opt}(l)=2$. Untuk menunjukkan batas atas, didefinisikan $l: V(G) \rightarrow\{1,2\}$ sebagai berikut :

$$
\begin{gathered}
l\left(x_{i}\right)=1 \\
l\left(y_{i}\right)=\left\{\begin{array}{c}
1, \text { untuk } i \text { gasal } \\
2, \text { untuk } i \text { genap }
\end{array}\right. \\
l\left(z_{i, j}\right)=\left\{\begin{array}{c}
1, \text { untuk } j=1 \\
2, \text { untuk } j=2
\end{array}\right.
\end{gathered}
$$

Sehingga $\operatorname{opt}(l)=2$ dan fungsi bobot sebagai berikut :

$$
\begin{gathered}
\qquad w^{i}\left(x_{i}\right)=\left\{\begin{array}{l}
3, \text { untuk } i=1 \text { dan } i=n \\
4, \text { untuk } i \text { gasal } \\
5, \text { untuk } i \text { genap }
\end{array}\right. \\
w^{i}\left(y_{i}\right)=\left\{\begin{array}{l}
5, \text { untuk } n \text { gasal } \\
6, \text { untuk } n \text { genap }
\end{array}\right. \\
w^{i}\left(z_{i, j}\right)=\left\{\begin{array}{l}
2, \text { untuk } i \text { gasal dengan } j=1 \\
3, \text { untuk } i \text { gasal dengan } j=2, i \text { genap dengan } j=1, \text { dan } i=n \text { dengan } j=2 \\
4, \text { untuk } i \text { genap dengan } j=2 \text { dan } i=n \text { dengan } j=2
\end{array}\right.
\end{gathered}
$$

Dari hasil diatas didapatkan batas atas, $\left|w^{i}\left(V\left(F_{n, 4}\right)\right)\right| \leq 5$. Selanjutnya, dari Lemma 1.1. dan Observasi 1.1. sebagai batas bawah menunjukkan bahwa $\chi_{l i s}^{i}\left(F_{n, 4}\right) \geq \chi_{l i s}\left(F_{n, 4}\right)=5$. Berdasarkan batas atas dan batas 
bawah menghasilkan nilai $5 \leq \chi_{l i s}^{i}\left(F_{n, 4}\right) \leq 5$, sedemikian sehingga $\chi_{l i s}^{i}\left(F_{n, 4}\right)=5$. Sehingga pembuktian telah selesai.

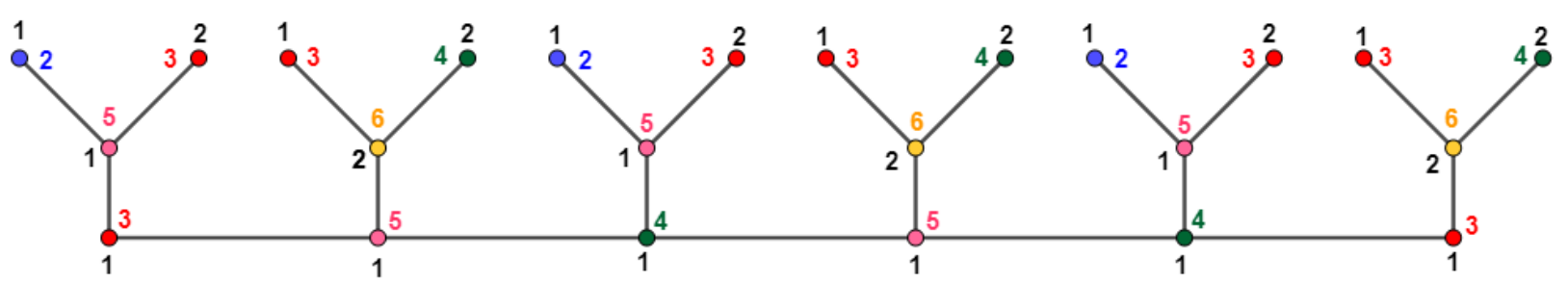

Gambar 1. Pewarnaan Titik Ketakteraturan Lokal Inklusif Graf Petasan $\chi_{l i s}^{i}\left(F_{n, 4}\right)=5$.

Theorem 3. Diberikan $S L_{n}$ adalah graf matahari dengan $n \geq 4$ maka

$$
\chi_{\text {lis }}^{i}= \begin{cases}3, & \text { untuk } n \text { genap } \\ 5, & \text { untuk } n \text { ganjil }\end{cases}
$$

Bukti. Diketahui $S L_{n}$ merupakan graf matahari dengan himpunan titik $V\left(S L_{n}\right)=\left\{x_{i} ; 1 \leq i \leq n\right\} \cup$ $\left\{y_{i} ; 1 \leq i \leq n\right\}$ dan himpunan sisi $E\left(S L_{n}\right)=\left\{x_{i} x_{i+1}, ; 1 \leq i \leq n\right\} \cup\left\{x_{i} y_{i} ; 1 \leq i \leq n\right\}$. Kardinalitas titik dan sisi memiliki nilai yang sama yaitu $\left|V\left(S L_{n}\right)\right|=\left|E\left(S L_{n}\right)\right|=2 n$. Untuk setiap $v \in V\left(S L_{n}\right)$, jika titik $x_{i}$ dan $y_{i}$ dilabeli dengan 1 maka menghasilkan $w^{i}\left(x_{i}\right)=l\left(x_{i}\right)+l\left(x_{i+1}\right)+l\left(x_{n}\right)+l\left(y_{i}\right)=4$ dan $w^{i}\left(x_{i+1}\right)=l\left(x_{i}\right)+l\left(x_{i+1}\right)+l\left(x_{i+2}\right)+l\left(y_{i+1}\right)=4$ sehingga didapatkan titik - titik yang memiliki bobot titik sama, sedangkan diketahui bahwa pada graf matahari titik $x_{i}$ dan $x_{i+1}$ adalah titik - titik yang bertetangga. Kondisi ini bertentangan dengan definisi dimana $w^{i}\left(x_{i}\right) \neq w^{i}\left(x_{i+1}\right)$ sehingga $\operatorname{opt}(l)=2$. Dalam pembuktian ini terdapat dua kasus

Kasus 3.1. Untuk $n$ genap

Untuk menunjukkan batas atas, didefinisikan $l: V(G) \rightarrow\{1,2\}$ sebagai berikut :

$$
\begin{aligned}
& l\left(x_{i}\right)= \begin{cases}1, & \text { untuk } i \text { gasal } \\
2, & \text { untuk } i \text { genap }\end{cases} \\
& l\left(y_{i}\right)= \begin{cases}2, & \text { untuk } i \text { gasal } \\
1, & \text { untuk } i \text { genap }\end{cases}
\end{aligned}
$$

Sehingga $\operatorname{opt}(l)=2$ dan fungsi bobot sebagai berikut :

$$
\begin{aligned}
& w^{i}\left(x_{i}\right)= \begin{cases}7, & \text { untuk } i \text { gasal } \\
5, & \text { untuk } i \text { genap }\end{cases} \\
& w^{i}\left(y_{i}\right)=3
\end{aligned}
$$

Dari hasil diatas didapatkan batas atas untuk $n$ genap $\left|w^{i}\left(V\left(S L_{n}\right)\right)\right| \leq 3$. Selanjutnya, dari Lemma 1.1. dan Proposisi 1.2 didapatkan batas bawah yang menunjukkan bahwa $\chi_{l i s}^{i}\left(S L_{n}\right) \geq \chi_{l i s}\left(S L_{n}\right)=3$. Berdasarkan batas atas dan batas bawah menghasilkan nilai $3 \leq \chi_{\text {lis }}^{i}\left(S L_{n}\right) \leq 3$, sedemikian sehingga $\chi_{l i s}^{i}\left(S L_{n}\right)=3$. Sehingga pembuktian telah selesai.

Kasus 3.2. Untuk $n$ gasal

Untuk menunjukkan batas atas, didefinisikan $l: V(G) \rightarrow\{1,2\}$ sebagai berikut : 


$$
\begin{aligned}
& l\left(x_{i}\right)=1 \\
& l\left(y_{i}\right)=\left\{\begin{array}{lc}
1, & \text { untuk } i \text { gasal } \\
2, & \text { untuk } i \text { genap } \\
3, & \text { untuk } i=n
\end{array}\right.
\end{aligned}
$$

Sehingga $\operatorname{opt}(l)=2$ dan fungsi bobot sebagai berikut :

$$
\begin{aligned}
& w^{i}\left(x_{i}\right)= \begin{cases}4, & \text { untuk } i \text { gasal } \\
5, & \text { untuk } i \text { genap } \\
6, & \text { untuk } i=n\end{cases} \\
& w^{i}\left(y_{i}\right)=\left\{\begin{array}{lc}
2, & \text { untuk } i \text { genap } \\
3, & \text { untuk } i \text { gasal } \\
4, & \text { untuk } i=n
\end{array}\right.
\end{aligned}
$$

Dari hasil diatas didapatkan batas atas untuk $n$ gasal $\left|w^{i}\left(V\left(S L_{n}\right)\right)\right| \leq 5$. Selanjutnya, dari Lemma 1.1. dan Proposisi 1.2 didapatkan batas bawah yang menunjukkan bahwa $\chi_{l i s}^{i}\left(S L_{n}\right) \geq \chi_{l i s}\left(S L_{n}\right)=5$. Berdasarkan batas atas dan batas bawah menghasilkan nilai $5 \leq \chi_{\text {lis }}^{i}\left(S L_{n}\right) \leq 5$, sedemikian sehingga $\chi_{l i s}^{i}\left(S L_{n}\right)=5$. Sehingga pembuktian telah selesai.

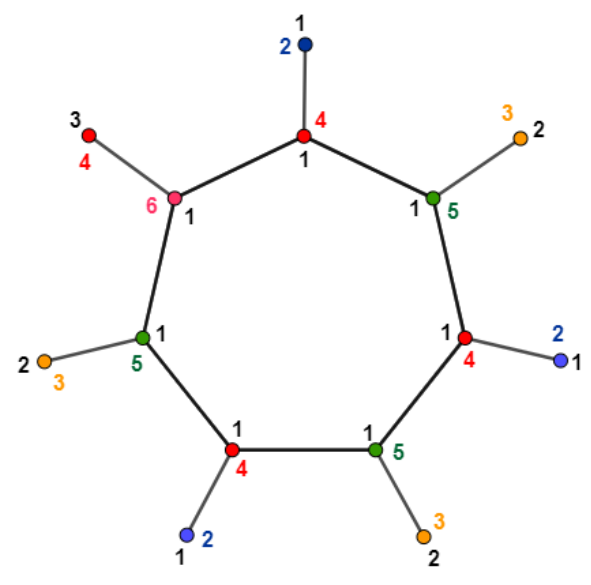

(a)

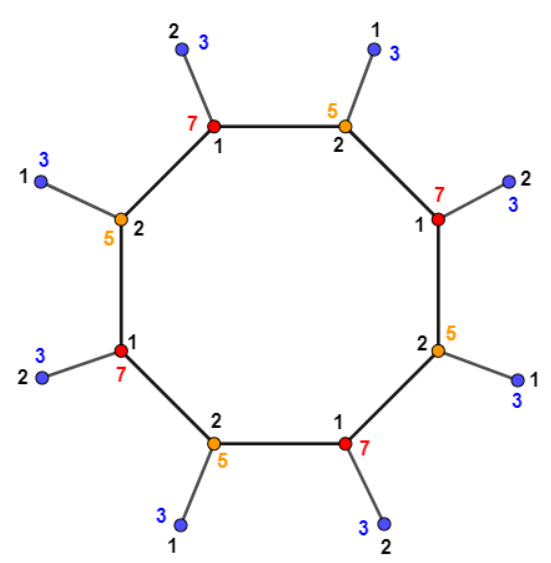

(b)

Gambar 3. Pewarnaan Titik Ketakteraturan Lokal Inklusif : (a) Graf matahari $\chi_{l i s}^{i}\left(S L_{8}\right)=3$; (b) Graf matahari

$$
\chi_{l i s}^{i}\left(S L_{7}\right)=5
$$

\section{KESIMPULAN}

Berdasarkan pembahasan diatas, diperoleh pewaranaan titik ketakteraturan lokal inklusif pada graf kipas, graf petasan, dan graf matahari serta menemukan bilangan kromatik ketakteraturan lokal inklusif dari graf tersebut yaitu $\chi_{l i s}^{i}\left(F_{n}\right)=4, \chi_{l i s}^{i}\left(F_{n, 4}\right)=5$, dan. $\chi_{l i s}^{i}\left(S L_{7}\right)=5$.

\section{UCAPAN TERIMA KASIH}

Kami mengucapkan terima kasih yang sebesar-besarnya atas dukungan dari LP2M dan Fakultas Keguruan dan Ilmu Pendidikan Universitas Jember Indonesia tahun 2021. 


\section{DAFTAR PUSTAKA}

[1] Reinhard. Diestel, Graph theory. Springer, 2000.

[2] G. Chartrand, C. Egan, and P. Zhang, "How to Label a Graph,” 2019. [Online]. Available: http://www.springer.com/series/10030

[3] Gary. Chartrand, P. Zhang, and Gary. Chartrand, A first course in graph theory. Dover Publications, 2012.

[4] O. Levin, Discrete mathematics : an open introduction, Third edition. 2019.

[5] Balakrishnan R and Ranganathan K, "A Textbook of Graph Theory,” 2012. [Online]. Available: http://www.springer.com/series/223

[6] A. I. Kristiana, Dafik, R. Alfarisi, U. A. Anwar, and S. M. Citra, "An inclusive local irregularity coloring of graphs," Advances in Mathematics: Scientific Journal, vol. 9, no. 10, pp. 8941-8946, 2020, doi: 10.37418/amsj.9.10.116.

[7] A. Indah Kristiana, M. I. Utoyo, Dafik, I. Hesti Agustin, R. Alfarisi, and E. Waluyo, "On the chromatic number local irregularity of related wheel graph," Journal of Physics: Conference Series, vol. 1211, no. 1, 2019, doi: 10.1088/17426596/1211/1/012003.

[8] U. Azizah Anwar, A. Indah Kristiana, A. Fatahillah, and R. Alfarisi, "Pewarnaan Ketakteraturan Lokal Inklusif pada Keluarga Graf Pohon Tree", doi: 10.25037/cgantjma.v2i1.49. 
